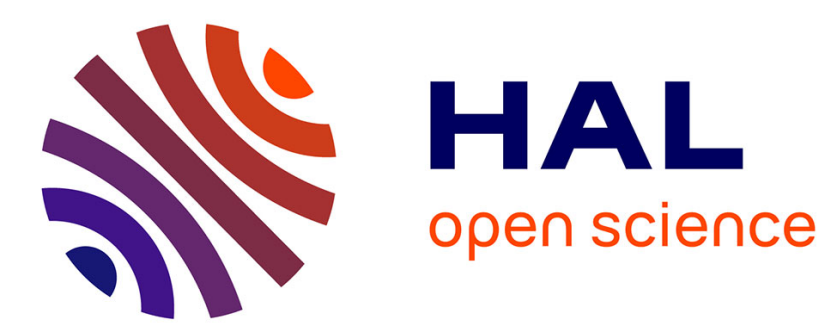

\title{
Anisotropic Marterials Prepared by CVD : Organic Molecular Conductors and High Tc Superconductors
}

\author{
A. Figueras
}

\section{To cite this version:}

A. Figueras. Anisotropic Marterials Prepared by CVD: Organic Molecular Conductors and High Tc Superconductors. Journal de Physique IV Proceedings, 1995, 05 (C5), pp.C5-347-C5-356. 10.1051/jphyscol:1995541 . jpa-00253868

\section{HAL Id: jpa-00253868 https://hal.science/jpa-00253868}

Submitted on 1 Jan 1995

HAL is a multi-disciplinary open access archive for the deposit and dissemination of scientific research documents, whether they are published or not. The documents may come from teaching and research institutions in France or abroad, or from public or private research centers.
L'archive ouverte pluridisciplinaire HAL, est destinée au dépôt et à la diffusion de documents scientifiques de niveau recherche, publiés ou non, émanant des établissements d'enseignement et de recherche français ou étrangers, des laboratoires publics ou privés. 


\title{
Anisotropic Materials Prepared by CVD: Organic Molecular Conductors and High $T_{c}$ Superconductors
}

\author{
A. Figueras \\ Institut de Ciència de Materials de Barcelona-CSIC, Campus de la UAB, 08193 Bellaterra, Spain
}

\section{1.- INTRODUCTION}

Low dimensional metals have lead to some of the most exciting developments in solid state physics in the past two decades. These systems can exhibit low temperature ground states such as charge density wave, spin density wave, and superconducting states and thus, can exhibit one or several transitions. Both organic charge transfer salts and inorganic oxide chalcogenides can exhibit this type of behaviour.

Tetrathiafulvalene (TTF:donor) and Tetracyanoquinodimethane (TCNQ:acceptor) form a chargetransfer complex (TTF-TCNQ) [1] which gives rise to a quasi-one-dimensional organic molecular conductor. The crystal structure of TTF-TCNQ is built from parallel chains of both donors and acceptors. The intermolecular spacing within these chains is short enough to allow the spreading of the lowest unoccupied molecular orbital (HOMO) of the donor and the lowest unoccupied molecular orbital (LUMO) of the acceptor into energy bands. The partial electron transfer from the TTF donor to the TCNQ acceptor leads to partially filled HOMO and LUMO bands and hence, to metallic conductivity.

TTF-TCNQ is a highly anisotropic molecular metal (with best conductivity along the chain direction) exhibiting two transitions at $T_{p}=54 \mathrm{~K}$ and $T_{p}=38 \mathrm{~K}$ which successively destroy the metallic conductivity of the TCNQ and TTF chains. These transitions originate from the well known Peierls type instability of strongly onedimensional metals [2].

Systematic work on the preparation and characterization of TTF-TCNQ layers is lacking. Most of the authors obtained the deposits by evaporation of the transfer salt in a chamber held at high vacuum $\left(10^{-5}-10^{-6}\right.$ torr). Although a rather complete description of the transport properties of the single crystal has been already reported, the electrical properties of TTF-TCNQ films are presently poorly understood. To our knowledge, there is just one paper [3] reporting a metallic behaviour up to $T_{p}$.

Relevant superconducting properties have been intensively investigated in copper oxide materials with critical temperatures ranging between 10 and $134 \mathrm{~K}$. Among these, $\mathrm{YBa}_{2} \mathrm{Cu}_{3} \mathrm{O}_{7}$ (a highly anisotropic two dimensional material), discovered by $\mathrm{Wu}$ et al [4] in 1987 is, up to now, the most studied superconducting material because of its excellent properties: ease of preparation as a single phase, high critical temperature $\left(\mathrm{T}_{c}=\right.$ $95 \mathrm{~K}$ ), high critical current in textured samples $\left(\mathrm{J}_{\mathrm{c}}=10^{6} \mathrm{~A} / \mathrm{cm}^{2}\right.$ at $\left.77 \mathrm{~K}\right)$, and no need to use highly toxic substances in its preparation.

MOCVD-YBa $\mathrm{Cu}_{3} \mathrm{O}_{7}$ thin films exhibit good behaviour in high magnetic fields (low dependence of $\mathrm{J}_{c}$ on magnetic field) because the type of pinning defects introduced in the MOCVD process. Among the defects, $a$-axis oriented domains included in a $c$-axis oriented matrix and yttria nanoprecipitates could play an important role in flux pinning. Nevertheless, the way in wich the distribution, shape, and size of these nanoprecipitates and other observed defects influence the transport properties of films still remains unknown and opens up an exciting field of research in MOCVD-grown HTSC films.

This paper deals with the preparation and characterization of TTF-TCNQ and $\mathrm{YBa}_{2} \mathrm{Cu}_{3} \mathrm{O}_{7}$ layers by CVD using TTF, TCNQ and $\mathrm{Y}, \mathrm{Ba}, \mathrm{Cu}$ B-diketones respectively as precursors. 


\section{EXPERIMENTAL}

2.1 Preparation of TTF-TCNQ layers

Commercial TTF and TCNQ previously recrystallized from acetonitrile, were used as source materials. They were coevaporated from stainless steel crucibles at $330 \mathrm{~K}$ and $393 \mathrm{~K}$ respectively and transported by a carrier gas (Ar) to the mixing area and then to the reaction zone. Ar flow through the source materials was maintained at $12.5 \mathrm{sccm}$ and a dilution flow of $12.5 \mathrm{sccm}$ was also introduced in the mixing zone, the temperature $\left(T_{w}\right)$ of which, measured on the quartz wall varied from $363 \mathrm{~K}$ to $403 \mathrm{~K}$. The total pressure in the reactor was kept at 1 torr.

Glass substrates of about $1 \mathrm{~cm}^{2}$ were glued with silver paste to a stainless steel body placed on the reaction zone. The holder was thermally heated at temperatures $\left(T_{s}\right)$ between $346 \mathrm{~K}$ and $354 \mathrm{~K}$. Layer thickness was evaluated by SEM.

Films were characterized by UV-visible spectroscopy, SEM and XRD. The dependence of the electric conductivity of the films on the temperature was also measured by a four-probe method.

\subsection{Preparation of stoichiometric and off-stoichiometry YBCO layers}

The films were grown on $\mathrm{SrTiO}_{3}(001)$ in a horizontal hot-wall reactor. B-diketonates such as $\mathrm{Y}(\mathrm{thd})_{3}, \mathrm{Cu}(\mathrm{thd})_{2}$ and $\mathrm{Ba}$ (thd $)_{2}$ were used as organometallic precursors. The layers were deposited at substrate temperatures $\left(T_{s u s}\right)$ ranged between 923 and $1093^{\circ} \mathrm{C}$. This large range of the deposition temperatures was used in the study of the kinetics of growth of the layers and in the analysis of the dependence of the preferential orientation in the crystallization with $\mathrm{T}_{\text {sus. }}$. The total pressure in the reaction chamber was 10 torr.

The experimental conditions for the preparation of quasi-stoichiometric layers were discussed elsewhere [5].

The non stoichiometric layers were grown at $\mathrm{T}_{\text {sus }}=1073 \mathrm{~K}$ on $\mathrm{SrTiO}_{3}$. The temperature of the $\mathrm{Ba}$ and $\mathrm{Cu}$ sources were held at $486 \mathrm{~K}$ and $376 \mathrm{~K}$ which correspond to adequate values for the preparation of stoichiometric layers. However, the temperature of $\mathrm{Y}$ precursor was varied in the range of 390 and $394 \mathrm{~K}$ in order to change the $\mathrm{Y}$ concentration in the gas phase which induces yttria nanoprecipitates in the deposited layers.

The thickness of the layers was varied between 300 and $500 \mathrm{~nm}$. The structure and the chemical composition of the films were obtained by XRD diffraction, TEM and electron microprobe, respectively. Superconducting properties of the films were measured by AC-susceptometer and SQUID.

\section{RESULTS AND DISCUSSION}

\subsection{Characterization of TTF-TCNQ films}

\subsubsection{Influence of gas phase concentration on the film stoichiometry}

Fig. 1 shows the general trend in the variation of the layer stoichiometry $(X)$ as a function of $\delta$ (ratio between evaporated TTF and TCNQ mass) for the deposition process performed at $T_{s}=348 \mathrm{~K}$ and $T_{m}=383 \mathrm{~K}$. As can be seen in the figure, stoichiometric films, $X=1$, are prepared at $\delta=1$ or even with a small excess of TTF in the gas phase. At $\delta>1$ the films are slightly TTF-rich, $X=1-1.03$. An increase in $\delta$ does not have a proportional influence on $\mathrm{X}$, indicating that the TTF excess is reevaporated. The vapour pressure of the TTF precursor at $\mathrm{T}_{\mathrm{s}}(346 \mathrm{~K}-350 \mathrm{~K})$ is high, consequently the reevaporation process of the TTF excess on the films must be relevant. It must also be noted that $\mathrm{X}$-ray diffraction analysis performed on these layers does not exhibit reflections corresponding to a TTF excess. 


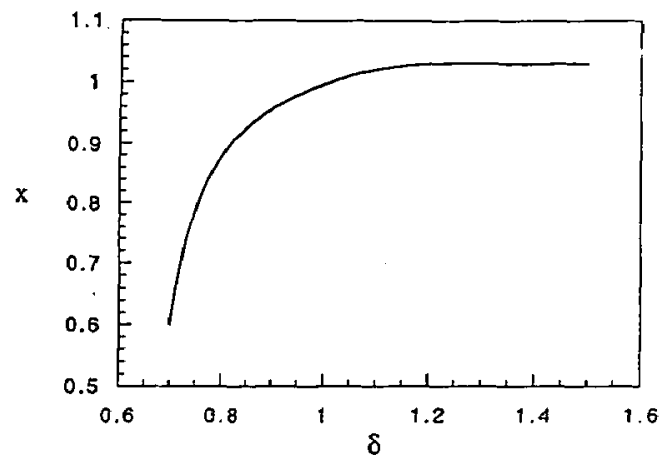

Figurel: Variation of the layers stoichiometry $(\mathrm{X})$ as a function of $\delta$ (ratio between evaporated TTF and TCNQ mass).

At $\delta<1$ the layers are not stoichiometric, they show an excess of TCNQ. However, reflections corresponding to a TCNQ excess were not found by $x$-ray diffraction. Thus, TCNQ are probably included in the films as very small cristallites. This result is consistent with the fact that $T_{s}$ is much smaller that the evaporation temperature of the TCNQ and even $T_{m}$. Therefore, condensation should be the process which controls the deposition of the excess of TCNQ in the vapour phase leading to small cristallites.

\subsection{Structure, texture and morphology of the layers}

Under well controlled experimental conditions the growth habit of TTF-TCNQ thin films leads to a strong preferential orientation in the crystallization. Nevertheless, due to small values of the interaction energies in the organic compounds, different stacking separations of the crystallographic planes could be obtained when preferential orientation is achieved. In this case, reflections in the X-ray diffraction pattern are shifted. In order to identify unambigously all the possible reflections, the TTF-TCNQ X-ray diffraction powder pattern was calculated from its crystal structure [6].

Fig. 2 shows the $X$-ray diffraction pattern of a $4 \mu \mathrm{m}$-thick layer prepared at $T_{s}=348 \mathrm{~K}$ and $T_{m}=383$ $\mathrm{K}$. The Miller indices of the reflections were unambigously assigned to the (002) and its homologues, indicating that the crystallites grow with the c-axis perpendicular to the substrate.

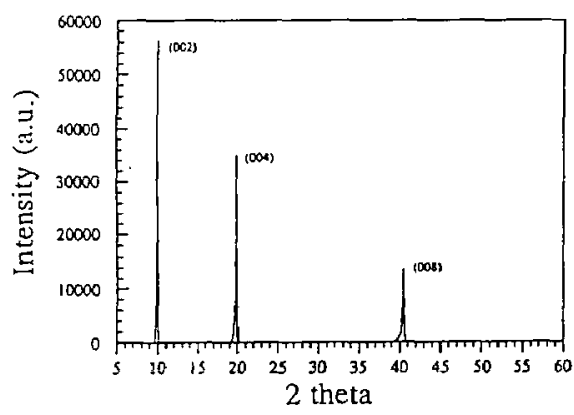

Figure 2: X-ray diffraction pattern of a TTF-TCNQ layer deposited at $\mathrm{T}_{\mathrm{S}}=348 \mathrm{~K}$.

The influence of the deposition temperature on the morphology, composition and structure of the films was checked over a short range of temperatures. Stoichiometric layers were obtained at deposition termperatures which ranged between $346 \mathrm{~K}$ and $350 \mathrm{~K}$ and $\mathrm{T}_{\mathrm{n}}$ held at $383 \mathrm{~K}$. The structure of the layers was the same as discussed previously. Texture analysis performed on the (013) reflection allowed the study the inplane orientation. In some cases, the crystallites showed a random distribution which exhibited twa lin: maxima separated by $180^{\circ}$; this direction on the substrate defined a line of maximum in-plane texture : 
could not be oriented with respect to the substrate because of its amorphous condition.

The morphology exhibited by the layers consists of a dense array of closely connected rectangular crystallites. It can be established, as a general trend, that the size of the crystallites increases with $T_{2}$. In our case this is true for a very narrow deposition temperature range.

As was pointed out by Volimann (7), beyond a certain thickness limit, the morphology of the layers changes abruptly because the influence of the substrate on the growth is shielded or completely lost. In our films this limit has been evaluated as $4 \mu \mathrm{m}$. The rectangular crystallites appearing in the initial stages of the growth coexist with very well developed dendrites with the faster growth direction perpendicular to the substrate. The layers become more porous, show lower mechanical consistency and the roughness of the surface is high. It should also be noted that in some cases the dendritic growth starts in the initial stages of growth, suggesting the existence of homogeneous nucleation in the gas phase. The 3D nuclei are transported to the substrate, inducing a fast growth.

\subsubsection{Electrical conductivity}

The electrical conductivity of the films was studied by means of four-probe measurements. Contacts consisted of four parallel graphite stripes applied to the surface of the films.

Fig. 3 shows the conductivities ( $\sigma$ ) vs temperature of the layers. In this figure, it has also been included the variation of $\sigma_{b}$ with temperature for a single crystal has also been included .

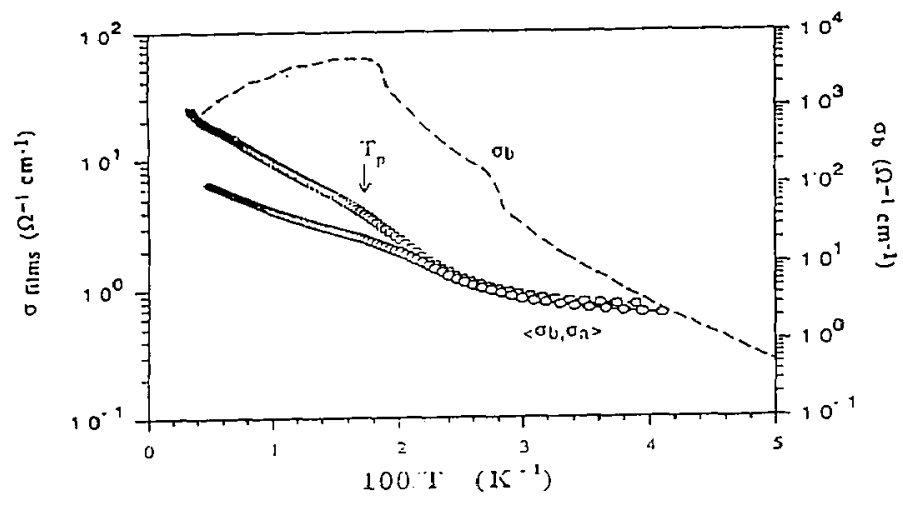

Figure 3: Conductivity vs temperature of the layers. The dashed line corresponds to the single crystal conductivity along $b$ axis.

Typical values of $\sigma_{b}$ in a single crystal at room temperature are $500-100 \Omega^{-1} \mathrm{~cm}^{-1}$. Even in the lowest electrical conductivity direction (a-axis), the TTF-TCNQ single crystal exhibits a room temperature conductivity $\sigma_{\mathrm{a}}$ of $1 \Omega^{-1} \mathrm{~cm}^{-1}$, which is high in comparison with most organic compounds. Our films show lower conductivity values $\left(6-24 \Omega^{-1} \mathrm{~cm}^{-1}\right)$ when compared to $\sigma_{b}$ of the single crystal, although they are very similar to other reported values [8].

The size of the crystallites are slightly different due to the variations in the deposition temperature. Chen et al [9] have studied the correlation between conductivity and crystallite size (L) in TTF-TCNQ layers deposited on glass. From their study it is clear that the difference in conductivity among the investigated samples does not seem to arise from the slight variation in stoichiometry nor from the distinct morphology of the films.

As it was discussed in 3.1.2, the films are preferentially oriented along the c-axis and thus, the electrical conductivity occurs in the "ab" crystalline planes. Therefore, the observed conductivity, $\sigma_{\text {cbs }}$, is a weighted average of the $\mathbf{a}$ and $\mathbf{b}$-axis conductivities.

If we assume a perfectly random crystallite distribution [9]

$$
\sigma_{o b s} \approx 2 \sigma_{2}
$$


The experimental values above $2 \sigma_{2}\left(\approx 2 \Omega \mathrm{cm}^{-1}\right)$ suggest a certain degree of texture along one direction (see paragraph 3.1.2).

As mentioned above, in the investigated temperature range (from $4.2 \mathrm{~K}$ up to $300 \mathrm{~K}$ ), the conductivity vs. temperature curve of the measured films displays a positive slope. However, the $\sigma(T)$ determination revealed that at $T=55-60 \mathrm{~K}$ an abrupt decrease of conductivity whith decreasing temperature occurs. A convenient way to evaluate the slope at $\mathrm{T}>60 \mathrm{~K}$ is by using an exponential law such as $\sigma=\sigma_{0}$ exp E/KT. It was determined that $E \approx 0.01 \mathrm{ev}$ and $E \approx 0.007 \mathrm{ev}$ in this high temperature range. These small values of the effective activation energies allow us to interpret the high temperature region of the $\sigma(T)$ curve, as reminiscent of the metallic behaviour observed in single crystals. In such a case the $T=55-60 \mathrm{~K}$ kink would correspond to $T_{p}$, and the non-metallic behaviour observed above $T_{p}$ is atributed to the presence of some randomly oriented and poorly connected crystallites.

At low temperatures (smaller than the transition temperature $T_{p}$ ) the films display a highly resistive semiconductor-like behaviour.

\subsection{Characterization of YBCO films}

\subsubsection{Kinetics of growth}

Fig. 4 shows the dependence of the YBCO deposition rate ( $\mathrm{r}$ ) on $\mathrm{SrTiO}_{3}(001)$ as a function of the deposition temperature. The small variation of $\mathbf{r}$ on $\mathrm{T}_{\text {sus }}$ suggest that the kinetics of growth is mainly controlled by the diffusion of the growth units into the substrate.

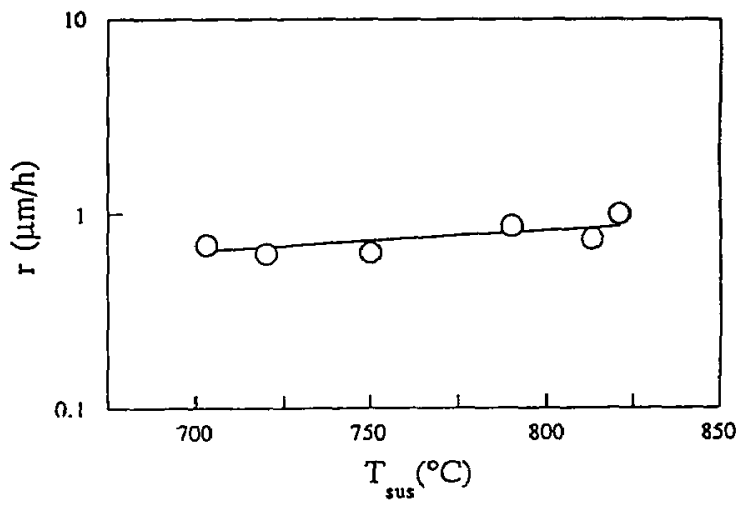

Figure 4: Dependence of kinetic of the deposition on the substrate temperature.

\subsubsection{Preferential orientation. Dependence on $T_{\text {sus }}$}

Fig. 5 shows the X-ray diffractograms of $\mathrm{YBCO}$ layers deposited on $\mathrm{SrTiO}_{3}(100)$ at three different temperatures. At lower temperature $(923 \mathrm{~K})$, the films exhibit a preferential orientation along the a-axis, which is perpendicular to the surface of the substrate. When $\mathrm{T}_{\text {sus }}$ increases, the preferential orientation changes gradually from a-axis to c-axis orientation. 


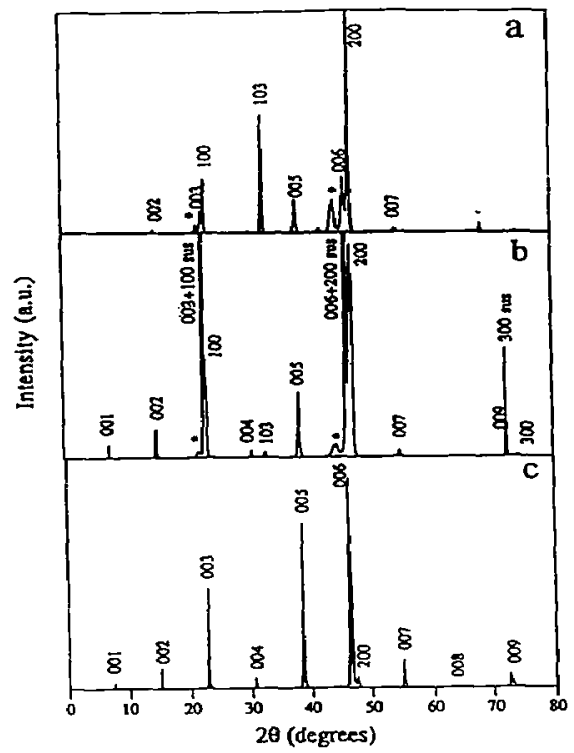

Figure 5: X-ray diffractograms of YBCO layers obtained at (a) $T_{m w}=923 \mathrm{~K}$, (b) $T_{m w}=998 \mathrm{~K}$, (c) $T_{n w}=1073 \mathrm{~K}$.

In order to analyse in more detail the change in the preferential orientation of the layers, we defined a texture parameter $\alpha_{\text {hd }}$ for every reflection (hkl) included in a preselected group: (005), (200) and (103), which are representative of the main possible orientations of $\mathrm{YBCO}$ on $\mathrm{SrTiO}_{3}(100)$

$$
\alpha_{\text {hkl }}(\%)=100 .\left(\mathrm{I}_{\mathrm{hkd}} / \mathrm{I}_{\text {hed }}^{\circ}\right) /\left(\Sigma\left(\mathrm{I}_{\mathrm{hkd}} / \mathrm{I}_{\mathrm{hkd}}^{\mathrm{o}}\right)\right)
$$

where $I_{\text {had }}$ and $I_{\text {hd }}^{\circ}$ are the normalized intensities of the (hkl) reflections corresponding to a specific layer and to the standard powder value, respectively. In our case, the $\alpha_{\mathrm{hb}}$ value should be an indirect measure of the volume $\%$ and equivalent mosaic spread of the different orientations considered. The variation of $\alpha_{\mathrm{bd}}$ as a function of the deposition temperature is depicted in fig. 6 .

Below $\mathrm{T}_{\mathrm{sx}}=1023 \mathrm{~K}$ the layers are mainly a-oriented. It was roughly estimated from the diffractogram that $88 \%$ vol were a-oriented domains. The percentage of c-oriented domains increases with increase in deposition temperature. Layers prepared at $1073 \mathrm{~K}$ show of $96 \%$ vol c domains.

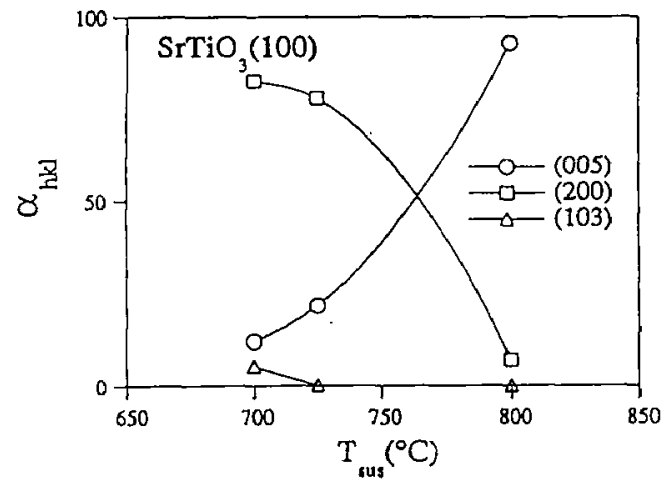

Figure 6: Evolution of the parameter $\alpha_{\text {hd }}$ with $T_{\text {sus }}$, for three different rellections.

\subsubsection{Quasi-stoichiometric c-oriented layers}

The mean value of the FWHM in the $c$-axis oriented layers was $0.5^{\circ}$ (measured on the (005) reflection). The 
texture of the c-oriented layers obtained at high deposition temperatures $\left(T_{\text {sus }}=1073 \mathrm{~K}\right.$ ) were studied by means of the (104)-YBCO pole figure. This reflection was chosen because it is off-plane and it does not overlap with any reflections coming from the substrate (for instance, (103)- $\mathrm{YBCO}$ and (110)-SrTiO$)_{3}$ ). The pole figure shows four spots indicating a four fold-symmetry with respect the c-axis. The domains are aligned with the principal directions of the substrate and they appear rotated $90^{\circ}$ around the c-axis [001].

HREM analysis of the a c-oriented layer grown on $\mathrm{SrTiO}_{3}$ with a composition 1:1.9:2.9 have shown that the relative orientation of the layer with respect to the substrate corresponds to

$$
[001]_{\mathrm{YBCO}} \|[001]_{\mathrm{STO}} \text { and }[100]_{\mathrm{YBCO}} \|[100]_{\mathrm{STO}}
$$

These epitaxial relations agree with the results obtained by texture analysis. A direct interface without dislocations in the material can also be observed. In the zone limited between the interface and up to $500 \mathrm{~nm}$ inside the film the periodicity of the material corresponds to the pure phase " $123^{\prime \prime}$ ( $c=11.7 \AA$ ) without observation of stacking faults and intergrowth of CuO planes. The critical temperature of these layers was $T_{c}$ (onset) $=91.5 \mathrm{~K}$ and the critical current density $\mathrm{j}_{\mathrm{c}}(77 \mathrm{~K}, 0 \mathrm{~T})\left(\mathrm{A} / \mathrm{cm}^{2}\right)=10^{6}$.

\subsubsection{Off-stoichiometric layers}

The layers were grown on $\mathrm{SrTiO}_{3}$ at $\mathrm{T}_{\text {sus }}=1073 \mathrm{~K}$ in order to obtain fully c-axis oriented films. The ratio $\mathrm{Cu} / \mathrm{Ba}$ was kept at $1.5 \pm 0.1$ and $\mathrm{Ba} / \mathrm{Y}$ varies from 1.6 to 2.4 .

As is well known, the film morphology is strongly affected by the variation of the $\mathrm{Cu} / \mathrm{Ba}$ ratio. $\mathrm{Cu}$ excess with respect to $\mathrm{Ba}$ provokes precipitates of $\mathrm{CuO}$ [10] which increase in size and density with increasing excess of copper.

In our films, the existence of $\mathrm{Y}_{2} \mathrm{O}_{3}$ precipitates for high concentration of $\mathrm{Y}$ have been detected by $\mathrm{X}$-ray diffraction $\left(2 \theta=34^{\circ}\right.$ identified as the (004) reflection of cubic $\mathrm{Y}_{2} \mathrm{O}_{3}$ ). These precipitates do not appear on the surface, suggesting that the excess of $Y$ is incorporated to the layers. It must also be noted that most of our films are slightly rich in copper, even if the ratio $\mathrm{Cu} / \mathrm{Ba}$ is kept at 1.5 , because the variation in \pm 0.1 is preferentially attributed a small Cu-excess. This fact leads to the formation, when the layers are Y-rich, of outgrows on the surface, assigned by XRD and electron microprobe analysis to $\mathrm{Y}_{2} \mathrm{Cu}_{2} \mathrm{O}_{5}$.

\subsubsection{Superconducting properties of $Y$-rich layers}

Zhao et al[11] have investigated compositional effects in YBCO layers obtained by PEMOCVD. Ba and-Cu rich layers were prepared by keeping the stoichiometric ratio for the other cations. The $T_{c}$ values did not degrade significately with a barium deficiency, while $T_{c}$ decreased as the barium concentration approached stoichiometric. In contrast, a copper excess up to $60 \%$ of the stoichiometric value did not substantially modify the $T_{c}$. Very little literature exists on $T_{c}$ measurements performed on $Y$-rich layers elaborated by MOCVD. Fig 7 depicts the evolution of $\mathrm{T}_{\mathrm{c}}$ as a function of the ratio $\mathrm{Ba} / \mathrm{Y}$ by mantaining $\mathrm{Ba} / \mathrm{Cu}$ in a range close to the stoichiometric one. In this case, the maximum $T_{c}$ is reached when the concentration approaches to the stoichiometry. This fact seems to indicate that the role of $\mathrm{Y}$ in the $\mathrm{Y}$-rich layers is different to which is played by the $\mathrm{Ba}$ and $\mathrm{Cu}$ in $\mathrm{Ba}$ and $\mathrm{Cu}$ off-stoichiometric layers where $\mathrm{T}_{\mathrm{c}}$ is maxima at off-stoichiometric compositions. 


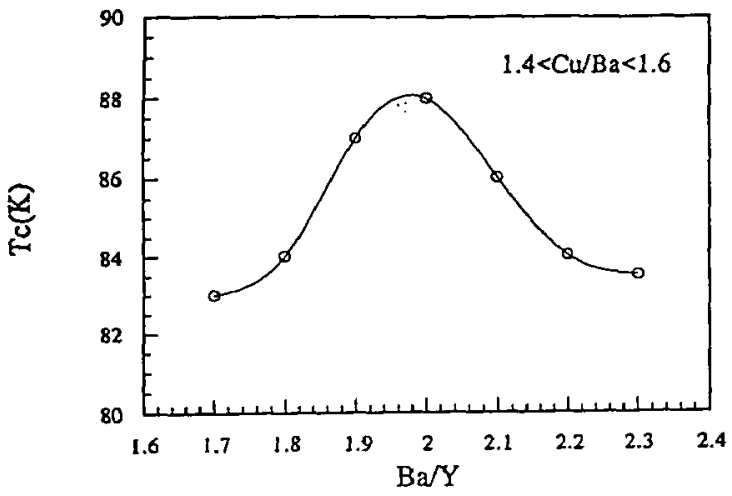

Figure 7: Evolution of the critical temperature (onset) with the ratio $\mathrm{Ba} / \mathrm{Y}$.

The dependence of $\mathrm{T}_{\mathrm{c}}$ with $\mathrm{Ba} / \mathrm{Y}$, in our layers, cannot be correlated with variations in its oxygen concentration. There is no dependence of the value of $\mathrm{c}-\mathrm{YBCO}$ parameter on the ratio $\mathrm{Ba} / \mathrm{Y}$. The $\mathrm{c}$ value measured for all the films is $11.67 \pm 0.01 \AA$, indicating that the layers were fully oxygenated.

The role of the $\mathrm{Y}_{2} \mathrm{O}_{3}$ precipitates as flux pinning centers was studied via the dependence of the critical current density on magnetic field, applied perpendicular to the $\mathrm{CuO}_{2}$ planes (in our case, these planes are parallel to the substrate). Fig. 8 shows the evolution of $\mathrm{j}_{c}$ at $5 \mathrm{~K}$ for two differents samples with $\mathrm{Ba} / \mathrm{Y}$ ratios corresponding to $(A)=2.35$ (low concentration of $\mathrm{Y}_{2} \mathrm{O}_{3}$ ) and $(B)=1.74$ (high concentration of yttria). The critical current density decreases from $4 \times 10^{6}$ to $5 \times 10^{5} \mathrm{Acm}^{-2}$ at $5 \mathrm{~T}$ (sample A) and from $1.2 \times 10^{7}$ to $5 \times 10^{5}$ $\mathrm{Acm}^{-2}$ at $5 \mathrm{~T}$ (sample B). Yttria precipitates seem to act as pinning centers, below $1.5 \mathrm{~T}$, enhancing the critical current density from $4 \times 10^{6}$ (Y-deficient layers) to $1.2 \times 10^{7}$ ( $Y$-rich layers) at $\mathrm{B}=0$. Above $1.5 \mathrm{~T}$, the evolution of $j_{c}$ with the magnetic field is similar for both layers, indicating that the mechanism of pinning varies and is probably related to the intrinsic quality of the material (density of dislocations...).

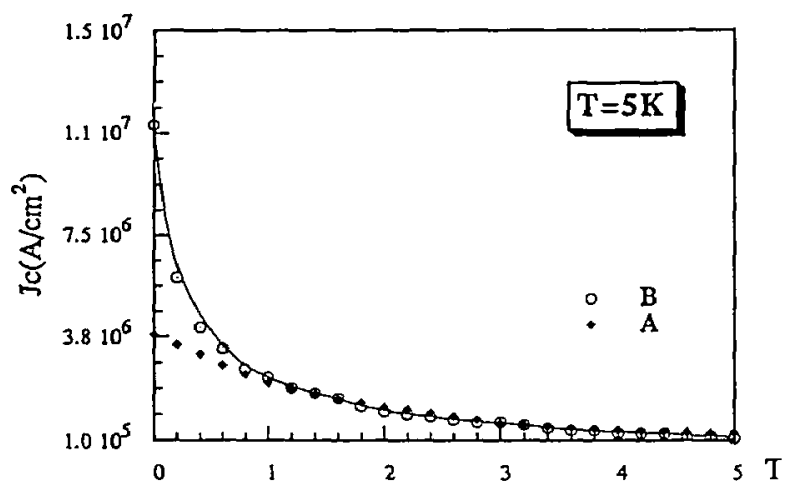

Figure 8: Dependence of $j_{c}$ with an extemal magnetic field, parallel to $Y B C O$-axis, measured in two samples, (a) $B a / Y=2.35$ (sample A), (b) BarY $=1.74$ (sample B).

It must be remembered that both samples have similar orientation, essentially the same density of twins and a-oriented domains but different densities of $\mathrm{Y}_{2} \mathrm{O}_{3}$ precipitates and second phases. At this stage is difficult to elucidate the mechanism of pinning because in this case $Y$-excess leads also to the production of $\mathrm{Y}_{2} \mathrm{Cu}_{2} \mathrm{O}_{3}$ precipitates. Nevertheless, a correlation exists between the introduction of yttria and the behaviour of $j_{c}$ with respect the magnetic field. In any case, our results agree with Li et al [12] and accurate texture, microstructure and transport characterizations must be carried out in order to elucidate unequivocally the pinning mechanisms at low and high magnetic field. 


\section{CONCLUSIONS}

\subsection{TTF-TCNQ layers}

1.- Good quality films of TTF-TCNQ were obtained on glass substrates by CVD using TTF and TCNQ. The evaporated precursors were transported to the reaction zone by a carrier gas (Ar). The resulting films are comparable to those obtained by evaporation at high vacuum $\left(10^{-6}\right.$ torr $)$.

2.- The stoichiometry of the layers was analyzed by UV visible spectroscopy. Stoichiometric films were prepared at substrate temperatures between $346-354 \mathrm{~K}$.

3.- The stoichiometry of the deposited material was controlled by varying the evaporation temperatures of the precursors in order to change their ratio in the vapor phase.

4.- The layers exhibit a preferential orientation in the cristallization along the [001] direction. In some cases, a direction of in-plane texture superposed to random oriented crystallites was detected.

5.- The electrical conductivity of the prepared films, although of positive slope from $4.2 \mathrm{~K}$ up to $300 \mathrm{~K}$, displays a pronounced kink at $T_{p} \approx 55-60 \mathrm{~K}$. Below $T_{p}$ the conductivity decreases steeply whereas above it, $\sigma(T)$ is weakly temperature dependent. We associate this temperature with the Peierls transition temperature observed in single crystals, which in the present case is masked by the presence of some randomly orientated crystallites.

\subsection{YBCO layers}

1.- The kinetics of growth of our YBCO layers are mainly controlled by the diffusion of the chemical species to the substrate $\left[\mathrm{SrTiO}_{3}(100)\right]$

2.- Different preferential orientations in the crystallization (a-axis and c-axis) can be established as function of the deposition temperature $\left(\mathrm{T}_{\text {sus }}\right)$. Below $\mathrm{T}_{\mathrm{sus}}=750^{\circ} \mathrm{C}$ the layers are mainly a-axis oriented.

3.- The quasi stoichiometric layers $(1: 2: 3)$ elaborated at high deposition temperatures $\left(\mathrm{T}_{\text {sus }}=800^{\circ} \mathrm{C}\right)$ show a $\mathrm{c}$-axis orientation. Texture analysis revealed that the domains are aligned with the principal directions of the substrate. Interfaces with substrate are direct without dislocations, stacking faults and intergrowth of $\mathrm{CuO}$ planes.

4.- The off-stoichiometric layers were prepared by changing the evaporation temperature of the $Y$-precursor. The variation of $T_{c}$ as a function of the ratio $\mathrm{Ba} / \mathrm{Y}$ (keeping $\mathrm{Ba} / \mathrm{Cu}=2 / 3$ ) is not correlated with a evolution in the oxygen content of the layers. The crystalline parameter $c$ was evaluated in $11.67 \pm 0.01 \AA$ indicating that all the films were fully oxygenated.

5.- Y-rich layers show precipitates that seem to act as pinning centers at low magnetic field (1.5 T). At higher values, mechanisms related with the intrinsic quality of the material seem to control the mechanism of pinning.

\section{CONCLUDING REMARKS}

CVD is an adequate technique for the preparation of unidimensional and two dimensional metals layers. The unusual transport properties of these materials are enhanced when elaborated as thin films. The control of the composition of the gas phase permits, in the case of the high $T_{c}$ superconducting materials the adjustment of the cationic composition of the YBCO films over a very wide range from stoichiometric ratio to ratios very far from this value. Smooth and continuous variations of the morphology and transport properties are thus obtained.

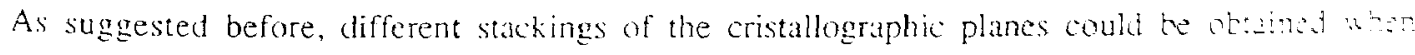


preferential orientations are achieved, due to small values of the interaction energies in the organic compounds. Small modifications of the deposition or mixing temperatures, carrier gas or other technological parameter could lead to small changes in the cristallographic structure which might induce modifications in the characteristics of the transitions. If this goal was obtained an interesting field of research should be explored.

\section{Acknowledgments}

The author thank Mr X.Llovet and L.Balo for carrying out some of the work and Dr. J.Fontcuberta for helpful discussions. We are also indebted to Prof. J. Sevely and Dr. S. Schamm from CEMES-LOE for TEM analysis. This work was partially supported by CICYT project MAT 468/92.

\section{References}

[1] Ferraris J., Cowan D.O., Walatka V., Perlstein J.H., J.Am.Chem.Soc. 95 (1973) 948

[2] Peierls R.E., Quantum Theory of Solids, Oxford University Press: Oxford (1952)

[3]Chaudari P. Scott B.A., Laibowitz R.B., Tomkiewicz Y., Torrance J.B., Appl. Phys. Letters 24 (1974) 439 [4]Wu M.K, Ashburn J.R., Torng C.J., Hor P.H., Meng R.L., Gao L., Huang J., Wang Y.Q., Chu C.W. Phys. Rev. Lett. 58 (1987) 908

[5]Santiso J., Figueras A. J.Physique N, C3 (1993) 353

[6]Kistenmacher T.J., Phillips T.E., Cowan D.O., Acta Cryst. B 30 (1974) 763

[7]Vollmann W, Berger W., Hamann C., Libera L., Thin Solid Films 111 (1984) 7

[8]Sumimoto T., Kudo K., Nagashiima T., Kuniyoshi S., Tanaka K., Synt. Metals 70 (1995) 1251

[9]Chen T.H., Schechtman B.H., Thin solid films 30 (1975) 173

[10]Schulte B., Maul M., Haüsler P., Adrian H., Appl. Phys. Lett. 62 (6) (1993) 633

[11]Zhao J., Norris P., Thin Solid Films 206 (1991) 122

[12]Li Y.Q., Zhao J., Chern C.S., Lu P., Gallois B., Norris P., Kear B., Cosandey F., Physica C 195 (1992) 161 